\title{
Serum ferritin is inversely correlated with serum adiponectin level: Population-based cross-sectional study
}

\author{
Bon-Jeong $\mathrm{Ku}^{\mathrm{a}}$, Seul-Young Kim ${ }^{\mathrm{a}}$, Tae-Yong $\mathrm{Lee}^{\mathrm{b}}$ and Kang-Seo Park ${ }^{\mathrm{c}, *}$ \\ ${ }^{a}$ Department of Internal Medicine, Chungnam National University School of Medicine, Daejeon, Korea \\ ${ }^{\mathrm{b}}$ Department of Preventive Medicine, Chungnam National University School of Medicine, Daejeon, Korea \\ ${ }^{\mathrm{c}}$ Department of Internal Medicine, Eulji University School of Medicine, Daejeon, Korea
}

\begin{abstract}
Background: The serum concentrations of ferritin and adiponectin are associated with several metabolic disorders and have been used as predictors of insulin resistance and metabolic syndrome. But there have been no reports demonstrating a direct correlation between serum ferritin and adiponectin levels. We performed this study to evaluate the association between serum ferritin and adiponectin concentrations.

Subjects and methods: We evaluated a total of 995 subjects from the Korea Rural Genomic Cohort Study in a population-based cross-sectional study. Extensive clinical and laboratory measurements, including adiponectin and ferritin concentrations, were recorded.

Results: Univariate analysis revealed that the serum adiponectin level was correlated with age, sex, BMI, diastolic blood pressure, triglyceride, HDL-cholesterol, fasting blood glucose, fasting insulin, HOMA-IR, hs-CRP, and ferritin. Multivariate analysis demonstrated that the adiponectin concentration was correlated with age, BMI, fasting glucose, hs-CRP, and ferritin. The ferritin concentration was the most powerfully associated with serum adiponectin. In non-diabetic subgroups, the adiponectin level was correlated with BMI, triglyceride, HDL-cholesterol, fasting glucose, and ferritin level in multivariate analysis. In diabetic subgroups, the adiponectin level was correlated with BMI, triglyceride, hs-CRP, and ferritin level in multivariate analysis. Conclusions: The serum adiponectin concentration was correlated with conventional clinical variables, but the most powerfully associated factor was the serum ferritin level.
\end{abstract}

Keywords: Adiponectin, ferritin, diabetes mellitus

\section{Introduction}

The serum ferritin concentration reflects the body's iron stores [1]. In previous studies, elevated serum ferritin levels were associated with several metabolic disorders. In a population study of Finnish men, serum ferritin levels were correlated with fasting serum glucose and insulin concentrations [2]. In a cross-sectional study of US adults, elevated iron stores were positively

* Corresponding author: Kang Seo Park, Department of Internal Medicine, Eulji University School of Medicine, 1306 Doonsan-dong, Seo-gu, Daejeon, 302-120 Korea. Tel.: +82 42798 6240; Fax: +82 42790 1275; E-mail: pkkss@eulji.ac.kr. associated with the prevalence of metabolic syndrome and with insulin resistance [3]. And in several other studies, researchers found that elevated serum ferritin concentrations were associated with cardiovascular disease [4,5], diabetes mellitus [6], gestational diabetes mellitus [7], and central adiposity [8,9].

Adiponectin, one of the adipocytokines, is secreted from adipose tissue [10]. Previous studies have reported that adiponectin plays a significant role in metabolic homeostasis [11]. Decreased serum adiponectin concentrations have been observed in patients with insulin resistance [12,13], diabetes mellitus [14], dyslipidemia [15], and metabolic syndrome [13,16]. Based on these results, the serum adiponectin level is considered a predictor of such metabolic disorders. 
Both serum ferritin and adiponectin levels were useful predictors of insulin resistance and metabolic syndrome $[3,13]$. But there are no reports demonstrating a direct correlation between serum ferritin and adiponectin levels. Therefore we evaluated the association between serum ferritin and adiponectin levels in normal and diabetic patients.

\section{Materials and methods}

\subsection{Study population}

Our study population comprised an age- and sexstratified random sample from the Korea Rural Genomic Cohort Study (Geumsan County). We conducted a population-based cross-sectional study. From January to February 2006, we studied a total of 995 subjects (417 males and 578 females) aged 40 to 80 years old (mean age $58.3 \pm 7.7$ years). Of the 995 subjects, 52 patients were excluded: those with any type of malignancy, those taking drugs that affect adiponectin level such as thiazolidinediones, and those with anemia, which was defined as a hemoglobin level less than $12 \mathrm{~g} / \mathrm{dl}$, or with iron deficiency anemia, which was classified by serum ferritin cutoff of $10 \mathrm{ng} / \mathrm{ml}$ in accordance with the World Health Organization definition [17]. Data from the remaining 943 subjects were analyzed, and data from 162 patients with diabetes mellitus were subanalyzed. Diabetes mellitus was diagnosed according to the criteria of the American Diabetes Association [18] or by the use of hypoglycemic agents.

Extensive clinical and laboratory screening was conducted for all participants. All participants gave their informed consent before entering the study. History and physical examination were obtained by personal interview. Blood pressure was measured on the right arm after at least 10 minutes of rest in a sitting position, using a standard mercury manometer. Height and weight were measured when the subjects were wearing light clothing and no shoes. Body mass index (BMI) was calculated as weight $(\mathrm{kg})$ divided by the square of the height $\left(\mathrm{m}^{2}\right)$. After these examinations, blood samples were drawn after an overnight fast. Blood specimens were stored at $4{ }^{\circ} \mathrm{C}$ and analyzed within 4 hours after collection.

\subsection{Laboratory experiments}

Complete blood counts were obtained using a Coulter counter (Coulter Electronics, Hialeah, FL, USA).
Triglyceride, total cholesterol, and HDL-cholesterol were measured enzymatically using a chemistry analyzer (Hitachi 747, Tokyo, Japan). LDL-cholesterol was calculated using the Friedewald formula [19]. Fasting plasma glucose was measured by the glucose oxidase method. Insulin was measured by immunoradiometric assay (Diabetes Primary Care, Los Angeles, CA, USA). Intra-assay coefficient of variation ranged from 2.41 to $2.93 \%$. Adiponectin was measured by radioimmunoassay (LINCO Research, Inc., St. Charles, MO, USA). Intra-assay coefficient of variation ranged from 7.55 to $14.26 \%$. Homeostasis model assessment (HOMA) estimate of insulin resistance was determined by the formula: HOMA-IR $=[$ insulin $(\mathrm{mU} / \mathrm{L}) \times$ glucose $(\mathrm{mmol} / \mathrm{L})] / 22.5$. High-sensitive C-reactive protein (hs-CRP) and ferritin were measured by enzyme immunoassay (Siemens Healthcare Diagnostics, Deerfield, IL, USA). Intra-assay coefficient of variation ranged from 2.11 to $3.00 \%$ in hs-CRP and from 5.0 to $10.0 \%$ in ferritin.

\subsection{Statistical analysis}

Continuous variables were expressed as the mean \pm standard deviation. Statistical analysis was performed using the commercially available program, Statistical Package for the Social Sciences (SPSS ${ }^{\circledR}$ ) (version 13.0; Chicago, IL, USA) for Windows ${ }^{\circledR}$. Comparisons between groups were performed using unpaired $t$-test or the chi-square test as appropriate. Linear regression analysis using the "stepwise" method was performed to evaluate the association between adiponectin and other clinical variables. A $P$ value of less than 0.05 was considered statistically significant.

\section{Results}

\subsection{Characteristics of the study population}

The clinical characteristics are listed in Table 1. The serum ferritin concentration was $108.0 \pm 107.4 \mu \mathrm{g} / \mathrm{L}$ in all subjects, $102.2 \pm 105.6 \mu \mathrm{g} / \mathrm{L}$ in non-diabetic subjects, and $135.3 \pm 112.1 \mu \mathrm{g} / \mathrm{L}$ in diabetic subjects. The serum ferritin concentration in diabetic subjects was significantly higher than in non-diabetics $(p=0.029)$. The serum adiponectin concentration was $11.58 \pm$ $5.63 \mu \mathrm{g} / \mathrm{mL}$ in all subjects, $11.96 \pm 5.70 \mu \mathrm{g} / \mathrm{mL}$ in non-diabetic subjects, and $9.72 \pm 4.91 \mu \mathrm{g} / \mathrm{mL}$ in diabetic subjects. The serum adiponectin concentration in diabetic subjects was significantly lower than in nondiabetics $(p=0.032)$. 
Table 1

Clinical characteristics of the subjects

\begin{tabular}{|c|c|c|c|c|}
\hline & All $(n=943)$ & $\begin{array}{c}\text { Non-diabetes } \\
\quad(n=782)\end{array}$ & $\begin{array}{c}\text { Diabetes } \\
(n=161)\end{array}$ & P value ${ }^{\S}$ \\
\hline Age (years) & $58.50 \pm 7.48$ & $58.23 \pm 7.59$ & $59.8 \pm 6.76$ & $0.021^{*}$ \\
\hline Sex $(\%$ of man $)$ & 43.4 & 41.7 & 51.2 & $0.260^{\dagger}$ \\
\hline Cerebral infarction $(\%)$ & 2.2 & 2.3 & 1.9 & $0.084^{\dagger}$ \\
\hline Myocardial infarction (\%) & 0.8 & 0.9 & 0.6 & $0.084^{\dagger}$ \\
\hline Heart failure $(\%)$ & 1.4 & 1.4 & 1.2 & $0.088^{\dagger}$ \\
\hline Hypertension (\%) & 25.0 & 21.9 & 40.1 & $<0.001^{\dagger}$ \\
\hline Current smoker (\%) & 18.8 & 18.6 & 19.8 & $0.983^{\dagger}$ \\
\hline Systolic blood pressure(mmHg) & $135.6 \pm 17.3$ & $134.8 \pm 17.4$ & $139.6 \pm 16.0$ & $0.057^{*}$ \\
\hline Diastolic blood pressure (mmHg) & $86.2 \pm 11.1$ & $86.0 \pm 11.3$ & $87.1 \pm 10.4$ & $0.624^{*}$ \\
\hline Body mass index (kg/m2) & $24.21 \pm 3.03$ & $24.07 \pm 3.05$ & $24.86 \pm 2.86$ & $0.469^{*}$ \\
\hline Triglyceride (mg/dl) & $178.6 \pm 108.9$ & $173.4 \pm 104.4$ & $203.5 \pm 125.6$ & $0.014^{*}$ \\
\hline HDL-cholesterol (mg/dl) & $48.0 \pm 11.3$ & $48.2 \pm 11.3$ & $46.8 \pm 11.0$ & $0.343^{*}$ \\
\hline LDL-cholesterol (mg/dl) & $128.0 \pm 33.9$ & $127.3 \pm 33.4$ & $131.4 \pm 36.2$ & $0.239^{*}$ \\
\hline Fasting blood glucose (mg/dl) & $97.0 \pm 22.9$ & $91.0 \pm 9.5$ & $126.0 \pm 40.3$ & $<0.001^{*}$ \\
\hline Insulin (mU/L) & $9.25 \pm 5.15$ & $9.02 \pm 4.89$ & $10.34 \pm 6.15$ & $0.002^{*}$ \\
\hline HOMA-IR & $2.26 \pm 1.60$ & $2.05 \pm 1.23$ & $3.27 \pm 2.52$ & $<0.001^{*}$ \\
\hline HbA1c $(\%)$ & $5.77 \pm 0.75$ & $5.55 \pm 0.34$ & $6.84 \pm 1.14$ & $<0.001^{*}$ \\
\hline Hemoglobin (g/dl) & $14.4 \pm 1.2$ & $14.3 \pm 1.2$ & $14.7 \pm 1.2$ & $0.994^{*}$ \\
\hline hs-CRP (mg/L) & $2.15 \pm 5.12$ & $1.84 \pm 3.69$ & $3.66 \pm 9.20$ & $<0.001^{*}$ \\
\hline Ferritin $(\mu \mathrm{g} / \mathrm{L})$ & $108.0 \pm 107.4$ & $102.2 \pm 105.6$ & $135.9 \pm 112.3$ & $0.029^{*}$ \\
\hline Adiponectin $(\mu \mathrm{g} / \mathrm{mL})$ & $11.58 \pm 5.63$ & $11.96 \pm 5.70$ & $9.72 \pm 4.91$ & $0.032^{*}$ \\
\hline
\end{tabular}

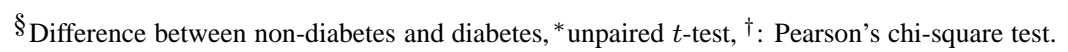

Table 2

Univariate analysis between the serum concentration of adiponectin and many clinical and laboratory parameters in all subjects

\begin{tabular}{|c|c|c|c|c|}
\hline & \multicolumn{2}{|c|}{ Correlation coefficient } & \multicolumn{2}{|c|}{$\begin{array}{l}\text { Partial correlation } \\
\text { coefficient }\end{array}$} \\
\hline & $\mathrm{R}$ & $\mathrm{P}$ value & $\mathrm{r}$ & $P$ value \\
\hline Age & 0.106 & 0.001 & & \\
\hline Sex & 0.336 & $<0.001$ & & \\
\hline Body mass index & -0.199 & $<0.001$ & -0.233 & $<0.001$ \\
\hline Systolic blood pressure & -0.050 & 0.127 & -0.044 & 0.174 \\
\hline Diastolic blood pressure & -0.067 & 0.039 & -0.026 & 0.425 \\
\hline Triglyceride & -0.241 & $<0.001$ & -0.242 & $<0.001$ \\
\hline LDL-cholesterol & 0.000 & 0.983 & -0.061 & 0.061 \\
\hline HDL-cholesterol & 0.266 & $<0.001$ & 0.289 & $<0.001$ \\
\hline Fasting blood glucose & -0.201 & $<0.001$ & -0.168 & $<0.001$ \\
\hline Fasting insulin & -0.119 & $<0.001$ & -0.157 & $<0.001$ \\
\hline HOMA-IR & -0.168 & $<0.001$ & -0.183 & $<0.001$ \\
\hline Ferritin & -0.222 & $<0.001$ & -0.094 & $<0.001$ \\
\hline hs-CRP & -0.121 & $<0.001$ & -0.089 & $<0.001$ \\
\hline
\end{tabular}

$R=$ correlation coefficient; $r=$ partial correlation coefficient adjusted for age and sex.

\subsection{Correlation between serum adiponectin level and other parameters in all subjects}

Univariate analysis (Table 2) revealed that the serum adiponectin level was correlated with conventional clinical variables, including age, sex, BMI, diastolic blood pressure, triglyceride, HDL-cholesterol, fasting blood glucose, fasting insulin, and hs-CRP. HOMA-IR, which serves as an indicator of insulin resistance, was significantly correlated with the serum adiponectin con- centration ( $p<0.001)$. Moreover, serum ferritin concentration was also significantly correlated with the serum adiponectin level $(p<0.001)$. The correlation of adiponectin to ferritin levels as a scatter-plot diagram was presented in Fig. 1. After adjusting for age and sex, the serum adiponectin level was still correlated with BMI, triglyceride, HDL-cholesterol, fasting blood glucose, fasting insulin, HOMA-IR, hs-CRP, and serum ferritin concentration.

Multivariate analysis (Table 3) demonstrated that 
Table 3

Results of the multivariate linear regression analysis using serum adiponectin level as the dependent variable in all subjects

\begin{tabular}{|c|c|c|c|c|}
\hline & \multicolumn{2}{|c|}{$\begin{array}{c}\text { Unstandardized } \\
\text { coefficients }\end{array}$} & \multirow{2}{*}{$\begin{array}{r}\begin{array}{r}\text { Standardized } \\
\text { coefficients }\end{array} \\
\text { Beta }\end{array}$} & \multirow[t]{2}{*}{$\mathrm{P}$ value } \\
\hline & B & $\begin{array}{r}\text { Standard } \\
\text { error } \\
\end{array}$ & & \\
\hline Age & 69.004 & 23.421 & 0.092 & 0.003 \\
\hline Body mass index & -309.634 & 58.263 & -0.166 & $<0.001$ \\
\hline Fasting blood glucose & -34.728 & 7.721 & -0.141 & $<0.001$ \\
\hline hs-CRP & -69.935 & 34.269 & -0.064 & 0.042 \\
\hline Ferritin & -10.713 & 1.637 & -0.204 & $<0.001$ \\
\hline
\end{tabular}

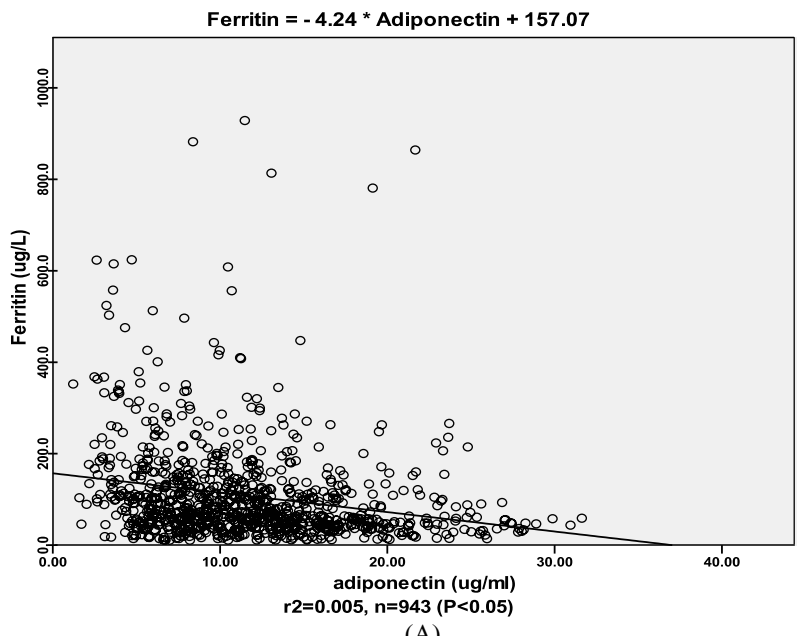

(A)

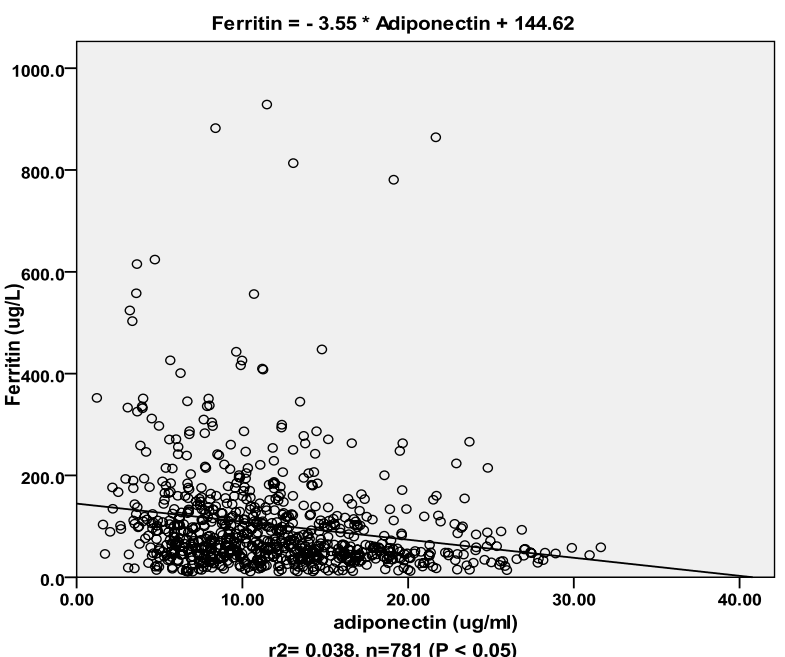

(B)

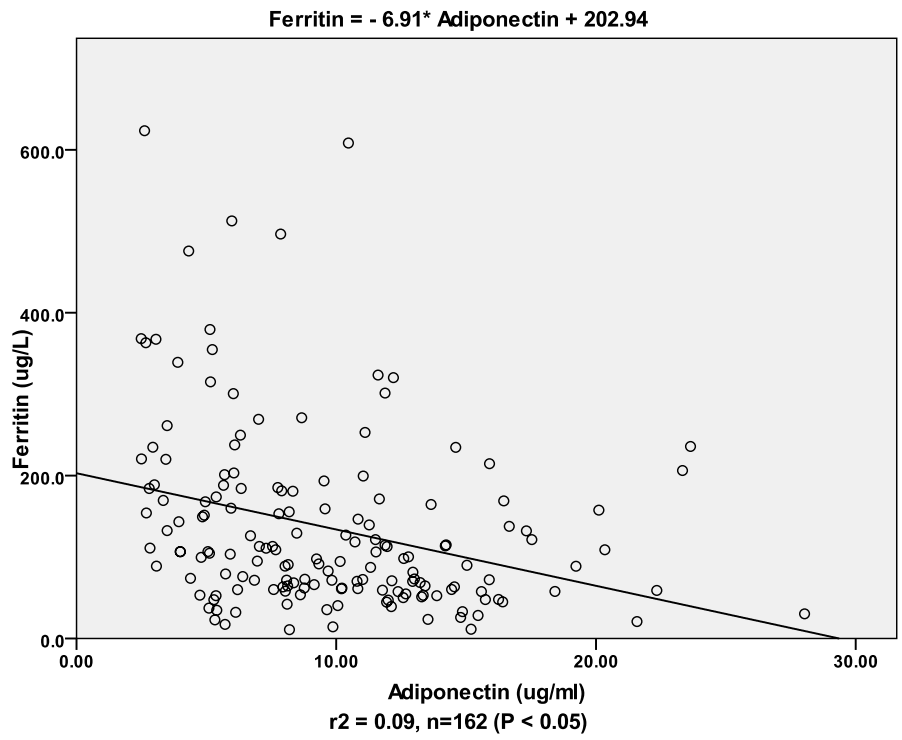

(C)

Fig. 1. Correlation of adiponectin to ferritin levels in (A) all subjects, (B) non-diabetic subjects, and (C) diabetic subjects. Scatter-plot diagram. 
Table 4

Univariate analysis between the serum concentration of adiponectin and many clinical and laboratory parameters in non-diabetic subjects

\begin{tabular}{lrrrrr}
\hline & \multicolumn{2}{c}{ Correlation coefficient } & & \multicolumn{2}{c}{$\begin{array}{c}\text { Partial correlation } \\
\text { coefficient }\end{array}$} \\
\cline { 2 - 3 } \cline { 5 - 6 } & \multicolumn{1}{c}{$\mathrm{R}$} & P value & & $\mathrm{r}$ & P value \\
\hline Age & 0.127 & $<0.001$ & & & \\
Sex & 0.333 & $<0.001$ & & & \\
Body mass index & -0.181 & $<0.001$ & & -0.215 & $<0.001$ \\
Systolic blood pressure & -0.032 & 0.363 & & -0.029 & 0.417 \\
Diastolic blood pressure & -0.049 & 0.174 & & -0.093 & 0.711 \\
Triglyceride & -0.223 & $<0.001$ & & -0.228 & $<0.001$ \\
LDL-cholesterol & 0.006 & 0.857 & & -0.055 & 0.123 \\
HDL-cholesterol & 0.278 & $<0.001$ & & 0.302 & $<0.001$ \\
Fasting blood sugar & -0.180 & $<0.001$ & & -0.139 & $<0.001$ \\
Fasting insulin & -0.089 & 0.012 & & -0.133 & $<0.001$ \\
HOMA-IR & -0.106 & 0.003 & & -0.140 & $<0.001$ \\
Ferritin & -0.191 & $<0.001$ & & -0.061 & 0.087 \\
hs-CRP & -0.082 & 0.021 & & -0.060 & 0.097 \\
\hline
\end{tabular}

$R=$ correlation coefficient; $r=$ partial correlation coefficient adjusted for age and sex.

Table 5

Results of the multivariate linear regression analysis using serum adiponectin level as the dependent variable in non-diabetic subjects

\begin{tabular}{|c|c|c|c|c|}
\hline & \multicolumn{2}{|c|}{$\begin{array}{c}\text { Unstandardized } \\
\text { coefficients }\end{array}$} & \multirow{2}{*}{$\begin{array}{r}\begin{array}{r}\text { Standardized } \\
\text { coefficients }\end{array} \\
\text { Beta }\end{array}$} & \multirow[t]{2}{*}{$\mathrm{P}$ value } \\
\hline & B & $\begin{array}{c}\text { Standard } \\
\text { error }\end{array}$ & & \\
\hline Body mass index & -208.340 & 63.960 & -0.111 & 0.001 \\
\hline Triglyceride & -5.858 & 1.927 & -0.107 & 0.002 \\
\hline HDL cholesterol & 114.133 & 17.417 & 0.227 & $<0.001$ \\
\hline Fasting glucose & -86.296 & 19.988 & -0.144 & $<0.001$ \\
\hline Ferritin & -9.085 & 1.820 & -0.168 & $<0.001$ \\
\hline
\end{tabular}

the serum adiponectin level was significantly correlated with age, BMI, fasting blood glucose, hs-CRP and serum ferritin concentration. The serum ferritin level was most powerfully associated with serum adiponectin $(B=-0.204)$

\subsection{Correlation between serum adiponectin level and other parameters in non-diabetic subjects}

In non-diabetic subgroups, univariate analysis (Table 4) revealed that the serum adiponectin concentration was correlated with clinical variables, including age, sex, BMI, triglyceride, HDL-cholesterol, fasting blood glucose, fasting insulin, HOMA-IR, hs-CRP and serum ferritin concentration.

Multivariate analysis (Table 5) demonstrated that the serum adiponectin concentration was significantly correlated with BMI, triglyceride, HDL-cholesterol, fasting glucose and serum ferritin concentration.

\subsection{Correlation between serum adiponectin level and other parameters in diabetic subjects}

In diabetic subgroups, univariate analysis (Table 6) revealed that the serum adiponectin concentration was correlated with clinical variables, including sex, BMI, triglyceride, HDL-cholesterol, fasting blood glucose, fasting insulin, HOMA-IR, hs-CRP and serum ferritin concentration.

Multivariate analysis (Table 7) demonstrated that the serum adiponectin concentration was significantly correlated with BMI, triglyceride, hs-CRP and serum ferritin concentration.

\section{Discussion}

In this study, we demonstrated a significant correlation between serum ferritin concentration and serum adiponectin concentration. The serum ferritin concentration was inversely correlated with the serum adiponectin concentration. 
Table 6

Univariate analysis between the serum concentration of adiponectin and many clinical and laboratory parameters in diabetic subjects

\begin{tabular}{lrrrrr}
\hline & \multicolumn{2}{c}{ Correlation coefficient } & & \multicolumn{2}{c}{$\begin{array}{c}\text { Partial correlation } \\
\text { coefficient }\end{array}$} \\
\cline { 2 - 3 } \cline { 5 - 6 } & \multicolumn{1}{c}{$\mathrm{R}$} & $\mathrm{P}$ value & & $\mathrm{r}$ & $\mathrm{P}$ value \\
\hline Age & 0.077 & 0.328 & & & \\
Sex & 0.316 & $<0.001$ & & \\
Body mass index & -0.227 & 0.004 & & -0.246 & 0.002 \\
Systolic blood pressure & -0.047 & 0.555 & & -0.054 & 0.503 \\
Diastolic blood pressure & -0.143 & 0.069 & & -0.094 & 0.242 \\
Triglyceride & -0.265 & 0.001 & & -0.276 & 0.001 \\
LDL-cholesterol & 0.005 & 0.950 & & -0.053 & 0.504 \\
HDL-cholesterol & 0.170 & 0.031 & & 0.195 & 0.014 \\
Fasting blood sugar & -0.200 & 0.011 & & -0.154 & 0.053 \\
Fasting insulin & -0.188 & 0.016 & & -0.208 & 0.009 \\
HOMA-IR & -0.237 & 0.002 & & -0.223 & 0.005 \\
Ferritin & -0.303 & $<0.001$ & & -0.188 & 0.018 \\
hs-CRP & -0.192 & 0.015 & & -0.140 & 0.080 \\
\hline
\end{tabular}

$R=$ correlation coefficient; $r=$ partial correlation coefficient adjusted for age and sex.

Table 7

Results of the multivariate linear regression analysis using serum adiponectin level as the dependent variable in diabetic subjects

\begin{tabular}{lccccc}
\hline & \multicolumn{2}{c}{$\begin{array}{c}\text { Unstandardized } \\
\text { coefficients }\end{array}$} & & $\begin{array}{c}\text { Standardized } \\
\text { coefficients }\end{array}$ & P value \\
\cline { 2 - 3 } \cline { 5 - 6 } & B & $\begin{array}{c}\text { Standard } \\
\text { error }\end{array}$ & & Beta & \\
\cline { 2 - 3 } & & & & & \\
\hline Body mass index & -317.862 & 125.082 & & -0.185 & 0.012 \\
Triglyceride & -9.213 & 2.937 & & -0.231 & 0.002 \\
hs-CRP & -83.474 & 39.233 & & -0.157 & 0.035 \\
Ferritin & -8.829 & 3.306 & & -0.202 & 0.008 \\
\hline
\end{tabular}

Adiponectin is a cytokine that is secreted from adipose tissue [11,20,21]. Adiponectin, also termed Acrp30, AdipoQ, or GBP28, structurally belongs to the complement q1 family and exists in blood as several types of multimers. Like changes in other adipocytokines, changes in the adiponectin level are related to several metabolic disorders.

According to a previous study, the serum level of adiponectin is associated with many clinical parameters. BMI, high-density lipoprotein, log triglyceride, fasting glucose, fasting insulin, fasting Cpeptide, and HOMA-IR were significantly correlated with adiponectin in African and Caucasian women [22]. BMI, HDL, apolipoprotein A1, apolipoprotein A2, plasminogen activator inhibitor-1 activity, TNF$\alpha$, and CRP were related to adiponectin in German patients [23]. BMI, fasting glucose, fasting insulin, HDL, triglyceride, CRP, insulin sensitivity, and visceral and subcutaneous adipose tissues were related to adiponectin in Hispanics and African-Americans [24]. BMI, fasting insulin, HDL and free fatty acids were also related to adiponectin in Japanese subjects [25]. Our results are similar to those of other studies. In our study, the concentration of adiponectin was related to BMI, triglyceride, HDL-cholesterol, fasting blood glucose, insulin, HOMA-IR, ferritin, and hs-CRP in univariate analysis. In multivariate analysis, age, BMI, fasting blood glucose, hs-CRP and ferritin were related to the serum adiponectin concentration. Ferritin was most powerfully correlated with adiponectin among these variables. To our knowledge, there are no previous reports about a direct correlation between ferritin and adiponectin.

In diabetic subjects, the adiponectin concentration was related to many clinical parameters. In Japanese diabetic subjects, BMI and triglyceride were correlated with adiponectin [26]. In US men with type 2 diabetes, HbA1c, TG, HDL, LDL, apoB100, CRP, and fibrinogen were correlated with adiponectin [27]. In our study, the adiponectin concentration was related to BMI, triglyceride, hs-CRP and ferritin in multivariate analysis. Triglyceride was most strongly correlated with the adiponectin concentration. In the case of ferritin, Sun et al. [28] reported that the adiponectin con- 
centration decreased according to the quartile of ferritin. However, they defined ferritin levels by quartiles, not by real values. The adiponectin concentration in diabetic subjects was significantly lower than in nondiabetic subjects, and the ferritin level in diabetic subjects was significantly higher than in non-diabetic subjects $[6,14,26]$. Our results are similar to those from other studies.

In conclusion, we demonstrated that ferritin is inversely correlated with serum adiponectin in all, nondiabetic and diabetic subjects. The biological mechanism for this association is not clear, but we can find one possible explanation in previous reports. Hypoadiponectinemia causes insulin resistance $[10,11]$ and hyperinsulinemia stimulates ferritin synthesis [29]. Hence we can hypothesize that hypoadiponectinemia can increase ferritin level. Decreased adiponectin levels are associated with many metabolic disorders [1216] and some cancers [30,31]. Thus we can use the serum adiponectin concentration as a predictor of such diseases. But the serum adiponectin level varies with measurement conditions such as storage time and temperature [32]. Therefore, if we use both ferritin and adiponectin levels, we can more accurately predict the development of several metabolic disorders and cancers.

This study has some limitations. We performed a cross-sectional study and measured total adiponectin levels, rather than low and high molecular forms. Also we did not determine the cutoff values of adiponectin and ferritin levels for predicting several metabolic diseases. Further studies are required to overcome these limitations.

\section{Acknowledgements}

This study is part of a nationwide cohort study undertaken to evaluate the risks of cardiovascular diseases and malignancies; it is supported by the Ministry of National Health and Welfare of the Republic of Korea.

\section{References}

[1] J.D. Cook, C.H. Flowers and B.S. Skikne, The quantitative assessment of body iron, Blood 101 (2003), 3359-3364.

[2] T.P. Tuomainen, K. Nyyssonen, R. Salonen, A. Tervahauta, H. Korpela, T. Lakka, G.A. Kaplan and J.T. Salonen, Body iron stores are associated with serum insulin and blood glucose concentrations. Population study in 1,013 eastern Finnish men, Diabetes Care 20 (1997), 426-428.
[3] M. Jehn, J.M. Clark and E. Guallar, Serum ferritin and risk of the metabolic syndrome in U.S. adults, Diabetes Care $\mathbf{2 7}$ (2004), 2422-2428.

[4] M. Haidari, E. Javadi, A. Sanati, M. Hajilooi and J. Ghanbili, Association of increased ferritin with premature coronary stenosis in men, Clin Chem 47 (2001), 1666-1672.

[5] M.J. Williams, R. Poulton and S. Williams, Relationship of serum ferritin with cardiovascular risk factors and inflammation in young men and women, Atherosclerosis 165 (2002), 179-184.

[6] E.S. Ford and M.E. Cogswell, Diabetes and serum ferritin concentration among U.S. adults, Diabetes Care 22 (1999), 1978-1983.

[7] X. Chen, T.O. Scholl and T.P. Stein, Association of elevated serum ferritin levels and the risk of gestational diabetes mellitus in pregnant women: The Camden study, Diabetes Care 29 (2006), 1077-1082.

[8] R.F. Gillum, Association of serum ferritin and indices of body fat distribution and obesity in Mexican American men-the Third National Health and Nutrition Examination Survey, Int J Obes Relat Metab Disord 25 (2001), 639-645.

[9] T. Iwasaki, A. Nakajima, M. Yoneda, Y. Yamada, K. Mukasa, K. Fujita, N. Fujisawa, K. Wada and Y. Terauchi, Serum ferritin is associated with visceral fat area and subcutaneous fat area, Diabetes Care 28 (2005), 2486-2491.

[10] T. Kadowaki and T. Yamauchi, Adiponectin and adiponectin receptors, Endocr Rev 26 (2005), 439-451.

[11] T. Kadowaki, T. Yamauchi, N. Kubota, K. Hara, K. Ueki and $\mathrm{K}$. Tobe, Adiponectin and adiponectin receptors in insulin resistance, diabetes, and the metabolic syndrome, J Clin Invest 116 (2006), 1784-1792.

[12] Y. Yamamoto, H. Hirose, I. Saito, K. Nishikai and T. Saruta, Adiponectin, an adipocyte-derived protein, predicts future insulin resistance: two-year follow-up study in Japanese population, J Clin Endocrinol Metab 89 (2004), 87-90.

[13] K. Hara, M. Horikoshi, T. Yamauchi, H. Yago, O. Miyazaki, H. Ebinuma, Y. Imai, R. Nagai and T. Kadowaki, Measurement of the high-molecular weight form of adiponectin in plasma is useful for the prediction of insulin resistance and metabolic syndrome, Diabetes Care 29 (2006), 1357-1362.

[14] M. Daimon, T. Oizumi, T. Saitoh, W. Kameda, A. Hirata, H. Yamaguchi, H. Ohnuma, M. Igarashi, M. Tominaga and T. Kato, Decreased serum levels of adiponectin are a risk factor for the progression to type 2 diabetes in the Japanese Population: the Funagata study, Diabetes Care 26 (2003), 2015-2020.

[15] M. Matsubara, S. Maruoka and S. Katayose, Decreased plasma adiponectin concentrations in women with dyslipidemia, $J$ Clin Endocrinol Metab 87 (2002), 2764-2769.

[16] W.S. Yang, W.J. Lee, T. Funahashi, S. Tanaka, Y. Matsuzawa, C.L. Chao, C.L. Chen, T.Y. Tai and L.M. Chuang, Plasma adiponectin levels in overweight and obese Asians, Obes Res 10 (2002), 1104-1110.

[17] E. DeMaeyer and M. Adiels-Tegman, The prevalence of anaemia in the world, World Health Stat Q 38 (1985), 302316.

[18] American Diabetes Association, Diagnosis and classification of diabetes mellitus, Diabetes Care 29(1) (2006), S43-S48.

[19] W.T. Friedewald, R.I. Levy and D.S. Fredrickson, Estimation of the concentration of low-density lipoprotein cholesterol in plasma, without use of the preparative ultracentrifuge, Clin Chem 18 (1972), 499-502.

[20] G.R. Hajer, T.W. van Haeften and F.L. Visseren, Adipose tissue dysfunction in obesity, diabetes, and vascular diseases, Eur 
Heart J 29 (2008), 2959-2971.

[21] N. Rasouli and P.A. Kern, Adipocytokines and the metabolic complications of obesity, J Clin Endocrinol Metab 93 (2008), S64-S73.

[22] A.E. Schutte, H.W. Huisman, R. Schutte, L. Malan, J.M. van Rooyen, N.T. Malan and P.E. Schwarz, Differences and similarities regarding adiponectin investigated in African and Caucasian women, Eur J Endocrinol 157 (2007), 181-188.

[23] D. Rothenbacher, H. Brenner, W. Marz and W. Koenig, Adiponectin, risk of coronary heart disease and correlations with cardiovascular risk markers, Eur Heart J 26 (2005), 1640-1646.

[24] A.J. Hanley, D. Bowden, L.E. Wagenknecht, A. Balasubramanyam, C. Langfeld, M.F. Saad, J.I. Rotter, X. Guo, Y.D. Chen, M. Bryer-Ash, J.M. Norris and S.M. Haffner, Associations of adiponectin with body fat distribution and insulin sensitivity in nondiabetic Hispanics and African-Americans, J Clin Endocrinol Metab 92 (2007), 2665-2671.

[25] M. Bluher, C.J. Williams, N. Kloting, A. Hsi, K. Ruschke, A. Oberbach, M. Fasshauer, J. Berndt, M.R. Schon, A. Wolk, M. Stumvoll and C.S. Mantzoros, Gene expression of adiponectin receptors in human visceral and subcutaneous adipose tissue is related to insulin resistance and metabolic parameters and is altered in response to physical training, Diabetes Care 30 (2007), 3110-3115.

[26] K. Hotta, T. Funahashi, Y. Arita, M. Takahashi, M. Matsuda, Y. Okamoto, H. Iwahashi, H. Kuriyama, N. Ouchi, K. Maeda, M. Nishida, S. Kihara, N. Sakai, T. Nakajima, K. Hasegawa, M. Muraguchi, Y. Ohmoto, T. Nakamura, S. Yamashita, T. Hanafusa and Y. Matsuzawa, Plasma concentrations of a nov- el, adipose-specific protein, adiponectin, in type 2 diabetic patients, Arterioscler Thromb Vasc Biol 20 (2000), 1595-1599.

[27] M.B. Schulze, E.B. Rimm, I. Shai, N. Rifai and F.B. Hu, Relationship between adiponectin and glycemic control, blood lipids, and inflammatory markers in men with type 2 diabetes, Diabetes Care 27 (2004), 1680-1687.

[28] L. Sun, O.H. Franco, F.B. Hu, L. Cai, Z. Yu, H. Li, X. Ye, Q. Qi, J. Wang, A. Pan, Y. Liu and X. Lin, Ferritin concentrations, metabolic syndrome, and type 2 diabetes in middle-aged and elderly chinese, J Clin Endocrinol Metab 93 (2008), 46904696.

[29] J.M. Fernández-Real, W. Ricart-Engel, E. Arroyo, R. Balanç, R. Casamitjana-Abella, D. Cabrero, M. Fernández-Castañer and J. Soler, Serum ferritin as a component of the insulin resistance syndrome, Diabetes Care 21 (1998), 62-68.

[30] A. Yildirim, M. Bilici, K. Cayir, V. Yanmaz, S. Yildirim and S.B. Tekin, Serum adiponectin levels in patients with esophageal cancer, Jpn J Clin Oncol 39 (2009), 92-96.

[31] D. Barb, C.J. Williams, A.K. Neuwirth and C.S. Mantzoros, Adiponectin in relation to malignancies: a review of existing basic research and clinical evidence, Am J Clin Nutr 86 (2007), s858-s866.

[32] K.M. Choi, J. Lee, K.W. Lee, J.A. Seo, J.H. Oh, S.G. Kim, N.H. Kim, D.S. Choi and S.H. Baik, Serum adiponectin concentrations predict the developments of type 2 diabetes and the metabolic syndrome in elderly Koreans, Clin Endocrinol (Oxf) 61 (2004), 75-80.

[33] T. Pischon, G.S. Hotamisligil and E.B. Rimm, Adiponectin: stability in plasma over 36 hours and within-person variation over 1 year, Clin Chem 49 (2003), 650-652. 


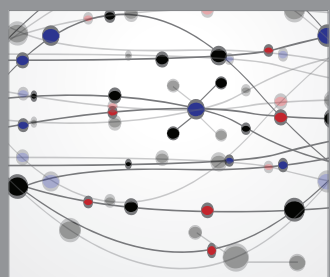

The Scientific World Journal
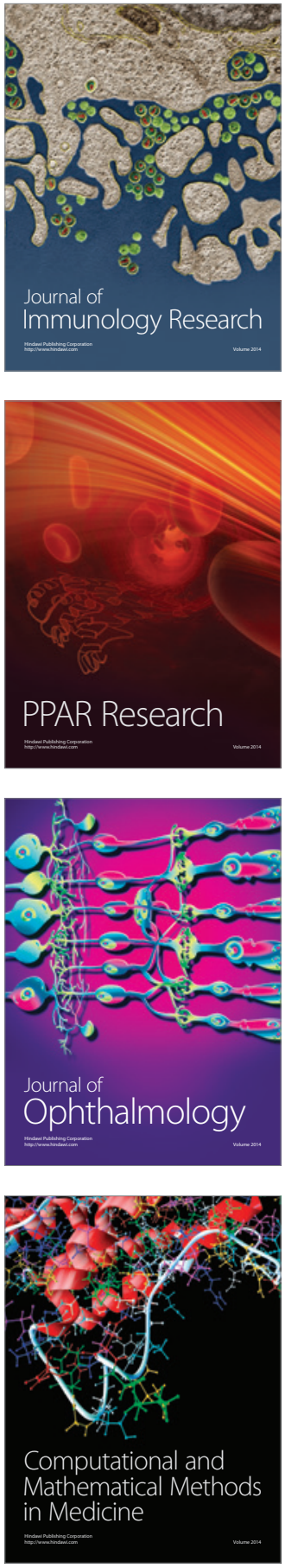

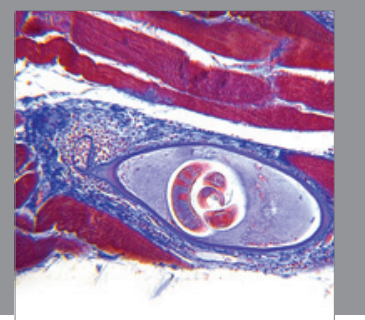

Gastroenterology

Research and Practice
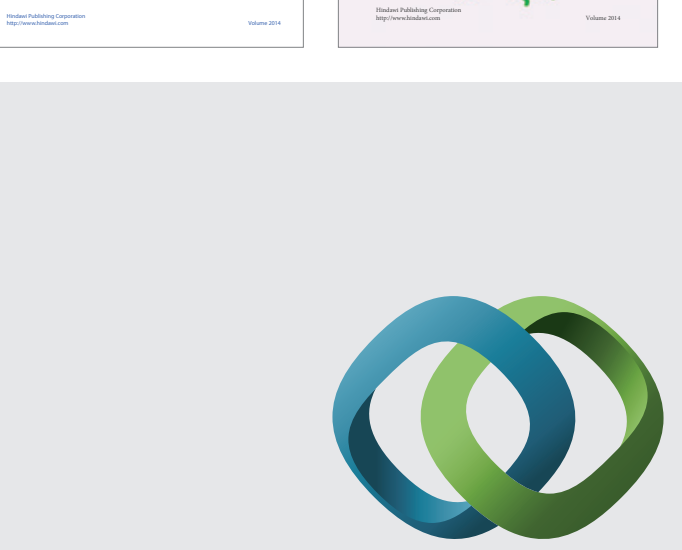

\section{Hindawi}

Submit your manuscripts at

http://www.hindawi.com
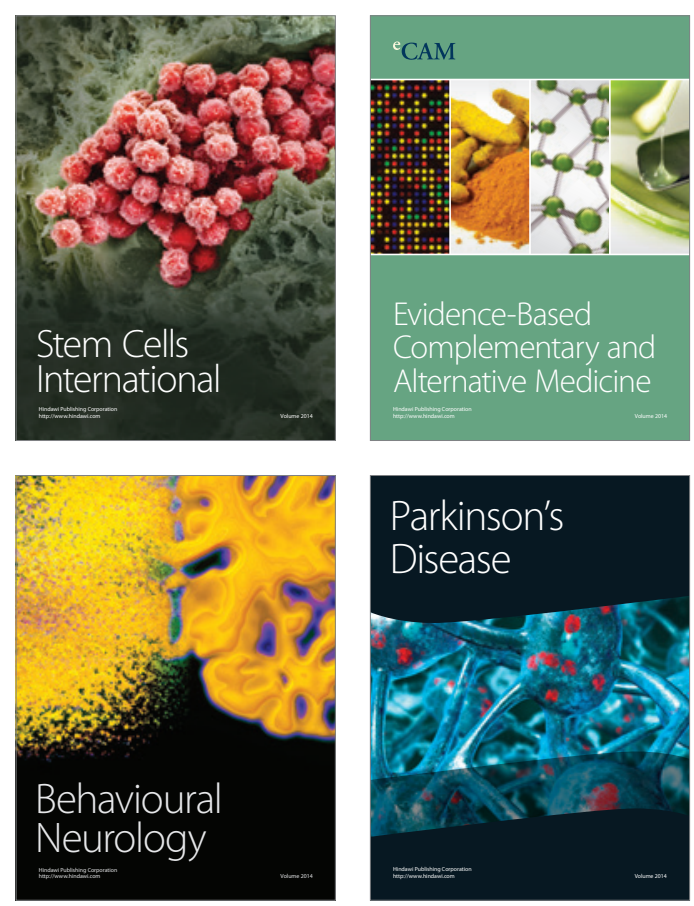

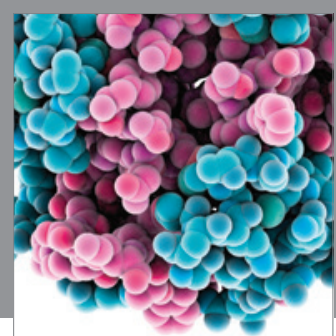

Journal of
Diabetes Research

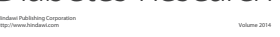

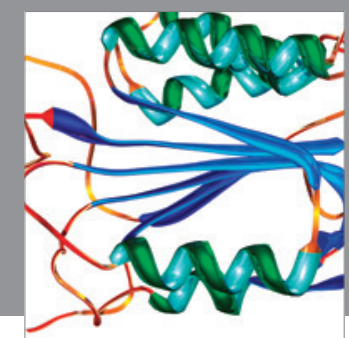

Disease Markers
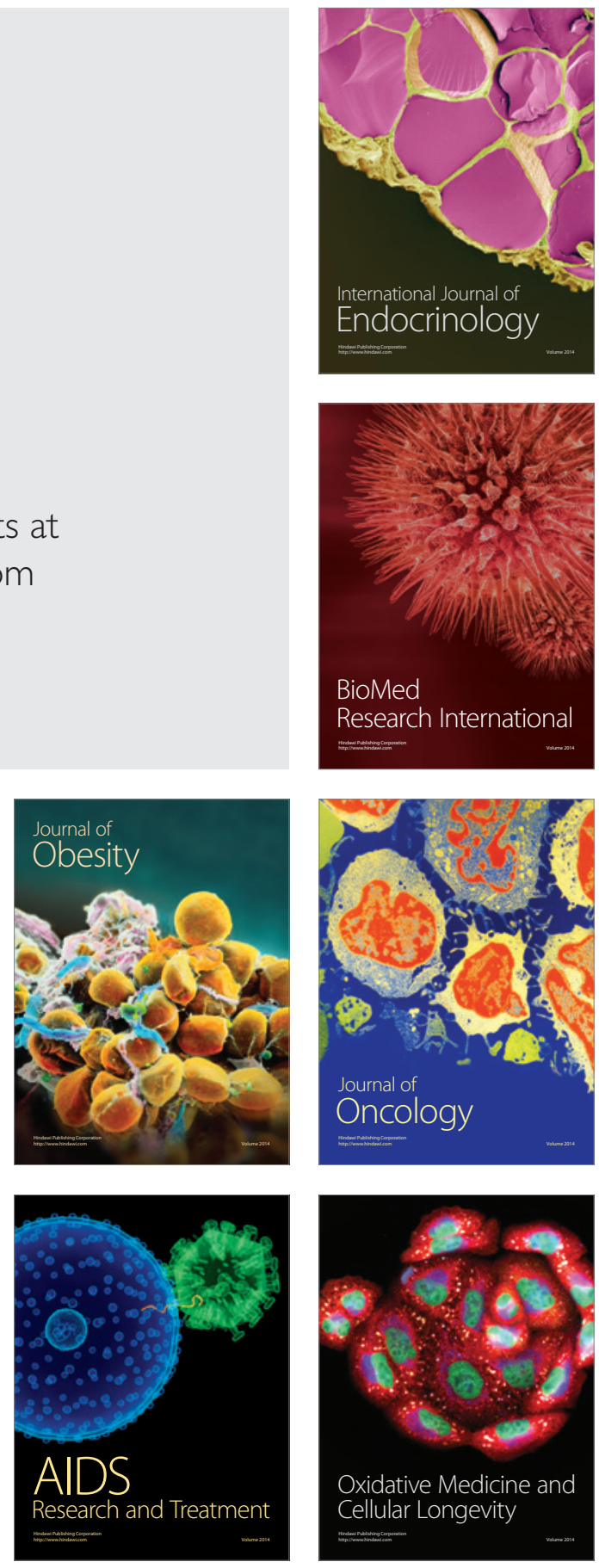